\title{
Modularity and integration in ontogeny of the middle facial skeleton in two West African monkey species: collared mangabey (Cercocebus torquatus) and olive colobus (Procolobus verus)
}

\author{
Andrej A. Evteev* \& Olga G. Nanova
}

\begin{abstract}
Could studying of a single bone's morphological variation and growth provide some additional information? For addressing this question a configuration of 13 landmarks from the middle part of the upper facial skeleton was digitized by Microscribe 3D digitizer on 25 skulls of Cercocebus torquatus and 16 skulls of Procolobus verus of different age and sex. Our results suggest that despite of strong ontogenetic integration in postnatal growth of the primate facial skeleton a study on a single bone's growth could provide a lot of biologically meaningful information. Elongation of the snout is far more pronounced in $C$. torquatus and related specifically to growth of the maxilla. This process can be described by a linear growth model and seems to be closely related to the general somatic growth rather than be by itself adaptive since an elongated snout could decrease bite force generation capacity at the incisors. Premaxillary growth is to a substantial degree independent from maxillary growth. The lower part of the bone attains its speciesspecific shape early in ontogeny what can be considered as a preparation to strong masticatory loadings which begin in this species during the first year of life. Later growth processes of the two bones are closely related and as a result shape of the premaxilla is substantially modified. Proximal and distal parts of the nasal bones seem to show differences: the former could be apparently different among individuals of the same species while shape and size of the later much more reflect elongation of the maxilla during postnatal period.
\end{abstract}

KEY WORDS: mid-facial ontogeny, Old World monkeys, geometric morphometrics.

Andrej A.Evteev[evteandr@gmail.com],Anuchin's Research Institute and Museum of Anthropology of the Moscow State University, Mokhovaya str. 11, Moscow 125009, Russia; Olga G. Nanova [nanova@mail.ru], Zoological Museum of the Moscow State University, Bol'shaya Nikitskaya str. 5/7, Moscow 125009, Russia.

\section{Модульность и интеграция в онтогенезе средней части лицевого скелета у двух видов западноафриканских обезьян: красноголового мангобея (Cercocebus torquatus) и зеленого колобуса (Procolobus verus)}

\begin{abstract}
А.А. Евтеев, О.Г. Нанова
РЕЗЮМЕ: Может ли изучение морфологической вариации и ростовых процессов отдельно взятой кости дать какую-то дополнительную информацию? В поисках решения этого вопроса мы оцифровали с помощью трехмерного дигитайзера Microscribe конфигурацию из 13 точек, расположенных в средней части верхнего лицевого скелета на 25 черепах Cercocebus torquatus и 16 черепах Procolobus verus различного пола и возраста. Наши результаты свидетельствуют, что, несмотря на сильно выраженную онтогенетическую интеграцию в постнатальном росте лицевого скелета приматов, изучение роста отдельно взятых костей может дать немало ценной с биологической точки зрения информации. Удлинение морды заметно сильнее выражено у C. torquatus и связано оно именно с ростовыми процессами верхнечелюстной кости. Этот процесс может быть успешно описан с помощью модели линейного роста и, по всей видимости, тесно связан с общими соматическими ростовыми процессами. Он, видимо, не имеет непосредственного адаптивного значения, так как удлинение морды может привести к снижению силы укуса резцов. Рост предчелюстной кости в значительной мере независим от роста максиллы. Нижняя часть этой кости принимает свою видоспецифичную форму в раннем онтогенезе, что может рассматриваться как «подготовка» к сильным жевательным нагрузкам, которые начинаются у представителей этого вида уже на первом году жизни. В дальнейшем ростовые процессы двух костей тесно связаны и, как результат, форма премаксиллы существенно модифицируется. Проксимальная и дистальная части носовых костей отличаются: форма первой может явно различаться у представителей одного вида, тогда как форма и размер второй в большей степени отражают удлинение верхнечелюстной кости в постнатальном онтогенезе
\end{abstract}

КЛЮЧЕВЫЕ СЛОВА: онтогенез лицевого скелета, обезьяны Старого Света, геометрическая морфометрия. 


\section{Introduction}

The concept of modularity is well established in evolutionary biology, particulary in evolutionary genetics, but distinguishing between different modules has always been a very challenging task when dealing with complex biological structures like mammalian skull (Cheverud, 1982; Altenberg \& Wagner, 1996). The results of numerous studies on the primate skull integration and modularity are often controversial. While most researches agree that cranial modules exist, there are many ways of dividing the whole structure into $a$ priori modules. Approaches to modularity greatly differ in terms of the number of modules, degree of comprehensiveness and theoretical basis. Each of the approaches has its own specificity (listed below) which strongly influences results of a study (Cheverud, 1982; Richtsmeier et al., 1993; Hallgrimsson et al., 2004; Cardini \& Elton, 2008a):

1) Mode of ossification: chondrocranium versus dermatocranium (Sperber, 2001; Cardini \& Elton, 2008a). The chondrocranial structures often serve as matrices for dermal bones and thus the shape of the later may depend on the shape of underlying elements of chondrocranium. A good example is relations between the nasal capsule and the nasal septum and dermal bones of the upper medial face in mammals (Latham, 1970; Mooney \& Siegel, 1986; Depew et al., 2005; Holton et al., 2010, 2011) and dependence of growth of the avian beak structures on the shape of the prenasal cartilage (Abzhanov et al., 2004; Wu et al., 2004). Another problem with such an approach is that a mode of ossification is correlated neither with embryonic origins nor genetic regulation or functions of bones. For instance, a part of the facial dermal bones is first branchial arch derivatives while the nasalia and the premaxilla originate from the neural crest cell populations from the forebrain area so their growth and development are controlled to a large degree independently (Creuzet et al., 2005; Depew et al., 2005).

2) "Big" modules: cranium versus the mandible, neurocranium versus viscerocranium, the upper face versus the middle face (Richtsmeier et al., 1993). Existence of these modules is obvious as well as the fact that this approach is too general since such modules are very heterogeneous inside themselves. On the other hand there is well established functional and genetic integration connecting these modules between each other (Cheverud, 1982; Lieberman et al., 2000; Bastir et al., 2006).

3) Functional modules selected according to main epigenetic effects of functional matrices - associated soft and hard tissues. This approach goes back to the classical works (Moss \& Young, 1960; Cheverud, 1982) and the set of the modules is admitted unchangeably in most studies. Despite it there are some challenging questions about any of these modules. For example, the eyeball undoubtedly plays a great role in early morphogenesis of the face integrating surrounding structures and stimulating its growth, but whether or not specific facial morphology of large-bodied animals depends on it, particularly taking into account relatively stable size of the eyeball in different species due to optical demands (Bunak, 1960; Enlow, 1975)? The results of several studies confirm that variation in size of the orbit is less than in surrounding structures (Richtsmeier et al., 1993; O’Higgins \& Jones, 1998) while measurements of the orbital module do not demonstrate a high level of integration (Cheverud, 1982). In the oral module its lower part, alveolar process, is undoubtedly affected by masticatory loadings but there are strong reasons to suppose an influence from the other functional matrix, nasal septum, onto its upper structures the palate and the nasal spine area (Latham, 1970; Mooney \& Siegel, 1986; Depew et al., 2005; Holton et al., 2010, 2011). The shape of the masticatory module depends not only on masticatory cyclic strain but also on the general somatic growth factors (Collard \& O'Higgins, 2001; Hallgrimsson et al., 2004; Bulygina et al., 2006; Funatsu et al., 2006) as well as on the shape of the cranial base (Bunak, 1960; Richtsmeier et al., 1993; Liebeman et al., 2000).

A relatively low level of integration in these functional modules was found in many studies (Cheverud, 1982; Cardini \& Elton, 2008a; Adams et al., 2011) and demonstrates that such an approach captures just a part (even though a very important part) of information about modularity of the facial skeleton and stimulates a search for new ways of separation of the whole structure into modules. Potentially a very promising way could be extracting modules according to the recent developmental genetics and experimental embryology data (Cardini \& Elton, 2008a).

In the present study we describe morphological variation and growth dynamics of single bones of the facial skeleton. This approach goes back to very old times. For instance C. Pearson wrote that a single bone's measurements might suit for the aim of a special anatomical research better than more "general" measurements (cited by Cheverud, 1982).

While warning from the use of single bones as modules, Moss and Young (1960) clearly demonstrated how complex the internal structure of a single bone might be and how different parts of the bone could vary independently. Growth processes of different facial bones taken separately described in works of D. Enlow (1966, 1975).

Here we deal with growth and morphology of three bones which form the middle part of the upper facial skeleton: the maxilla, the premaxilla and the nasal bone. There are several features of these bones which worth a special attention.

First, while being placed very close and forming an integrated structure, these bones (the maxilla versus the premaxilla and the nasalia) have different embryological origins and further different profiles of regulatory genes expression (see above). It means that in the early prenatal period before forming of rigid sutures each 


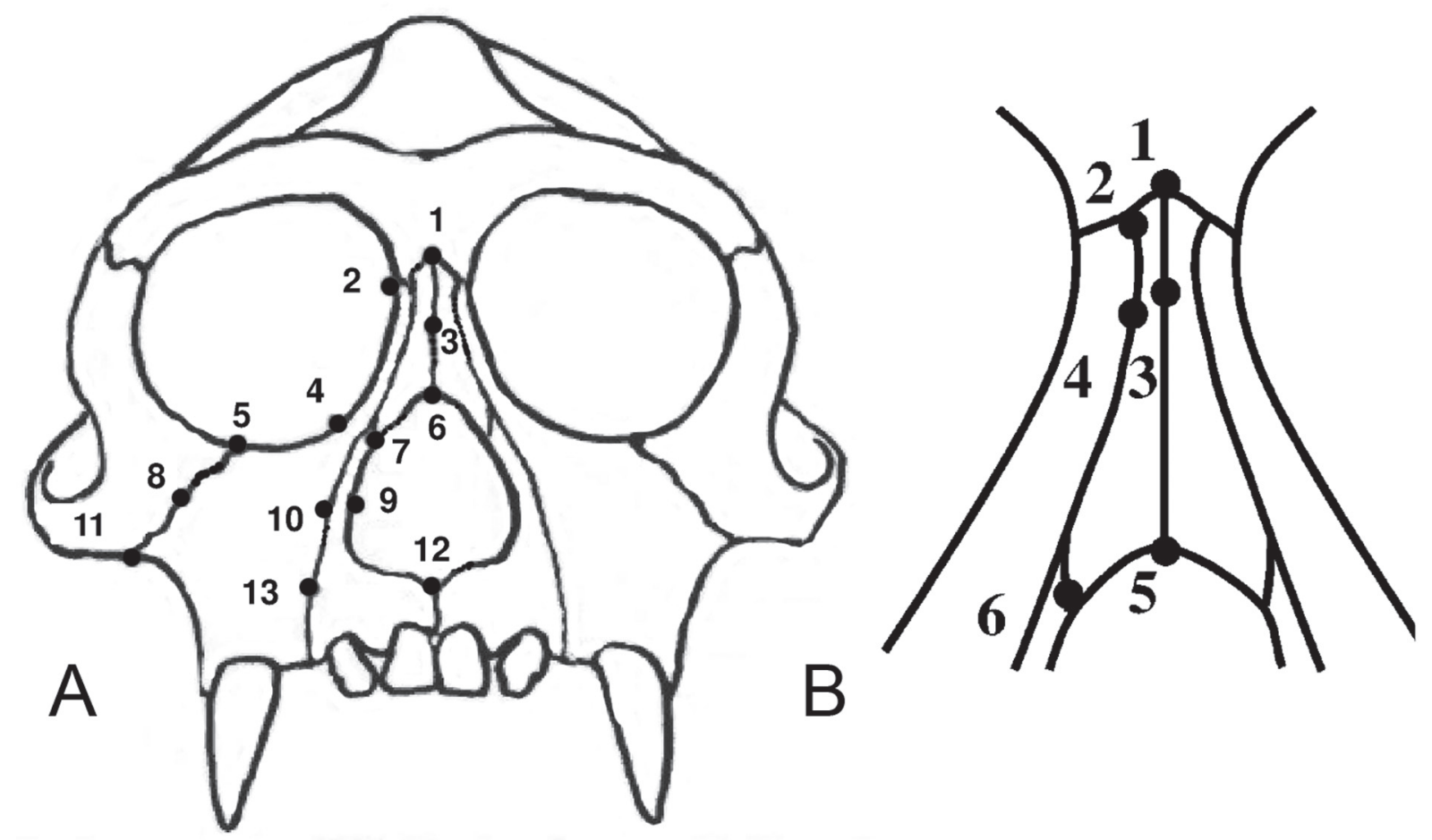

Figure 1. Facial landmarks used in the study: A — general configuration, 13 landmarks; B — the nasal bone configuration, 6 landmarks (for anatomical definition of the landmarks see Tab. 1).

bone attains a size according to its intrinsic growth rate and forms a bigger or a smaller part of the whole structure (Enlow, 1975; Depew et al., 2008; Marimoto et al., 2008; Rice, 2008). After a suture is formed bone deposition rates differ significantly at both sides of the suture thus the different bones continue to grow differently (Bjork, 1968; Rice, 2008).

Second, an intensive growth of these bones takes place at different stages of ontogeny. Both the premaxilla and the upper part of the nasal bones grow rapidly during the gestation so a morphological pattern of the midline facial structures is nearly developed by the end of the first year of life (Sysak, 1960; Schultz, 1963; Mooney \& Siegel, 1986; Richtsmeier et al., 1993; Franciscus, 1995). Human infant skulls from different populations can be classified nearly as correctly as the adults (Vidarsdóttir et al., 2002), and an individual pattern of the facial skeleton is also determined by the age of 3 years (Bulygina et al., 2006). Taking into account small size of the maxilla at this age the abovementioned differences can be attributed predominantly to the premaxilla and the nasalia morphology.

Finally, due to asynchronous growth, the bones are involved in different ontogenetic events and influenced by different functional matrices. The nasalia, the premaxilla and only a small part of maxilla grow in close relation to the nervous system (eye) and the respiratory (the nasal cavity through the nasal capsule and the nasal septum) organs formation while the main growth of the maxilla occurs in correspondence with far later events - molar and premolar emergence and pubertal growth spurt (Enlow, 1975; Richtsmeier et al., 1993; Funatsua et al., 2006; Bulygina et al., 2006). We believe that considering single bones' growth processes may add some additional arguments for the long-standing discussion about a relative importance of early pre- and perinatal growth versus postnatal growth in the facial skeleton ontogeny (Richtsmeier et al., 1993; O'Higgins \& Jones, 1998; Collard \& O’Higgins, 2001; Ponce de Leon \& Zollikofer, 2001; Ackermann \& Krovitz, 2002; O’Higgins \& Collard, 2002).

Since choice of a set of landmarks for a study is a crucial point of any research design (Oxnard \& O'Higgins, 2009) we followed some criteria while constructing the configuration:

1) Neurocranial landmarks were completely excluded from the configuration.

2) Points belonging to both the malar bone and the zygomatic arch, a "core" of conventional masticatory module (Cheverud, 1982; Richmond et al., 2005; Curtis et al., 2008), were also excluded. We have excluded points from the alveolar process as well since this structure is known to be particularly strongly influenced epigenetically (Enlow, 1975). Several studies have demonstrated that linear measurements with points lying on the alveolar process have very low narrowsense heritability (Cheverud, 1982; Martinez Abadias, 2007).

3) We tried to describe the middle part of the upper facial skeleton more comprehensively than it's usually 
done (O’Higgins \& Jones, 1998; Ackermann \& Krovitz, 2002; Hallgrimsson, 2004; Cardini \& Elton, 2008a) by digitizing some additional landmarks (Fig. 1).

At the stage of the analysis we pursued the following aims:

1) Describe the morphological variation and growth dynamics of each of three bones separately, assess their interaction throughout ontogeny and evaluate a contribution of each bone to the general morphology of the middle facial skeleton ("muzzle"). For this purpose we divided the general landmark configuration into configurations of the single bones such that some landmarks were included both to "maxilla" and "premaxilla" configurations (see "Materials and methods"). Then the principal component and other statistical analyses were performed for each bone independently.

2) Visualize results of the analyses performed for the single bones.

Most authors place figures representing morphological changes of a landmark configuration of the whole facial skeleton and anterior neurocranium in their articles (Richtsmeier et al., 1993; O’Higgins \& Jones, 1998; Hallgrimsson, 2004; Cardini \& Elton, 2008a). Such configurations include dozens of landmarks making their interpretation a challenging task. The most noticeable and strongly pronounced differences dominate while the smaller but not less important changes can be hardly noticed even with a careful examination of the graph. Publications of figures depicting single modules morphology are rare (Smith et al., 2007; Cardini \& Elton, 2008a). Another problem is that a visual output of a Geometric Morphometric Methods (GMM) analysis displays relative changes of adjacent structures and it's hard to distinguish growth of a certain bone from changes in its neighbours (O'Higgins et al., 2001). So, in analyses of single bones' pictures we were trying to capture growth changes of each bone separately.

Crania of two West-African monkey species Cercocebus torquatus (Kerr, 1792), fam. Cercopithecidae, subfam. Cercopithecinae and Procolobus verus (van Beneden, 1838), fam. Cercopithecidae, subfam. Colobinae - are an object of the study. The species have prominently distinct facial morphology. The face of the collared (white-collared, or sooty) mangabey ( $C$. torquatus) is prognathous and fairly elongated and thus is to some extent similar to the shape of the face in the baboon. A characteristic trait of all mangabeys is large incisors that are used for crushing hard food items such as nuts. The facial skeleton of the olive colobus $(P$. verus) is shortened as in all Colobinae. Sexual dimorphism in facial morphology is far more pronounced in $C$. torquatus than in $P$. verus. These morphological differences can be explained by size differences, ecological and phylogenetic divergence (Davies \& Oates, 1995). Male weight of $P$. verus is $3.3-5.7 \mathrm{~kg}$, female weight is $3-4.5 \mathrm{~kg}$; male weight of $C$. torquatus is 7 $12.5 \mathrm{~kg}$, female weight $5-8 \mathrm{~kg}$. The diet differs strongly between the two species. The diet of $P$. verus includes a substantial amount of soft food (young leaves, flowers) in contrast to the diet of the other Colobinae (Davies \& Oates, 1995). The diet of C. torquatus contains a lot of hard food. For example, fruits of Sacoglottis gabonesis which constitute the bulk of mangabey's diet are comparable in hardness to a cherrystone. These fruits are eaten by both young and adult monkeys. There is no difference in the diet between adult and young $C$. torquatus (McGraw et al., 2011).

Previous studies on these or similar species have clearly demonstrated differences in growth dynamics between the middle and the lateral parts of the monkey facial skeleton (O'Higgins \& Jones, 1998; Collard \& O’Higgins, 2001; O'Higgins \& Collard, 2002) as well as between different facial bones (Enlow, 1966; Cheverud, 1982; Corner \& Richtsmeier, 1991; Richtsmeier et al., 1993; O’Higgins \& Jones, 1998; Cobb \& O'Higgins, 2004). In the present study we have tried to assess ontogeny of single bones comprising the middle part of the facial skeleton more comprehensively. We would like to emphasize that the study was aimed neither to a general description of cranial growth of these species (which can be found elsewhere) nor to resolving of systematic and phylogenetic questions.

\section{Materials and methods}

Twenty five skulls of collared (sooty) mangabeys $C$. torquatus and 16 skulls of olive colobuses $P$. verus from the University of York, Functional morphology and Evolution unit collection were digitized using Microscribe G2X 3D digitizer. Skulls of the animals of all growth stages from juvenile to adulthood were included in the analysis. Details of sex and age of the specimens are given in Tab. 2. Full information about each $C$. torquatus individual's dentition eruption and abrasion can be found in the article of O'Higgins and Jones (1998).

Thirteen landmarks were collected from the middle part of the upper face of each skull (Fig. 1A, Tab. 1). The landmark configuration for the maxilla includes 8 landmarks: 2, 4, 5, 7, 8, 10, 11, 13. The landmark configuration for the premaxilla includes 5 landmarks: $7,9,10,12,13$. The nasal bones from 19 skulls $(P$. verus - 8, C. torquatus - 11) were digitized using a special set of landmarks for more comprehensive analysis of the nasal bone variation (Fig. 1B, Tab. 1). It must be pointed out that the results of this part of the study might be seriously biased due to uneven sampling: there are no fully adult females of $C$. torquatus and no juveniles of $P$. verus in the sample. Thus we did not apply ANOVA in this section but taking into account rarity of data on the nasal bones variation present the PCA and some other results.

Procrustes and Principal Component analyses were performed on the two species combined sample and for each species separately. For this purpose we used Morphologika 2.5 (O’Higgins \& Jones, 1998). Morphologika was also used for visualization of the results. A regression analysis between PCs scores and centroid size was 
Table 1. Anatomical definitions of landmarks.

\begin{tabular}{|c|c|c|c|}
\hline Number & Name & Definition & "Module" \\
\hline 1 & Nasion & The nasofrontal suture in the midline & \\
\hline 2 & \multirow{3}{*}{ Maxillofrontale } & The frontolacrimal suture at the medial orbital margin & Maxillae \\
\hline 3 & & $\begin{array}{l}\text { A point at the internasal suture at the level of minimal width of } \\
\text { the nasal bones }\end{array}$ & \\
\hline 4 & & $\begin{array}{l}\text { A point of intersection of tangent to the lateral edge of lacrimal } \\
\text { fossa and the inferior orbital edge }\end{array}$ & Maxillae \\
\hline 5 & Zygoorbitale & The zygomatico-maxillary suture at the inferior orbital margin & Maxillae \\
\hline 6 & Rhinion & Tip of the nasal bones in the midline & \\
\hline 7 & \multirow{2}{*}{ Nasomaxillare } & $\begin{array}{l}\text { The most inferior point of the nasomaxillary suture (the point is } \\
\text { very close to the superior point of the premaxillary frontal } \\
\text { process) }\end{array}$ & $\begin{array}{l}\text { Maxillae, } \\
\text { premaxillae }\end{array}$ \\
\hline 8 & & $\begin{array}{l}\text { The zygomaticomaxillary suture, a point of intersection with the } \\
\text { line which connects landmark } 10 \text { and the most inferior point of } \\
\text { the tempo-zygomatic suture (on the zygomatic arch) }\end{array}$ & Maxillae \\
\hline 9 & \multirow[b]{2}{*}{ Conchale } & Crista conchalis at the nasal aperture margin & Premaxillae \\
\hline 10 & & $\begin{array}{l}\text { The point of intersection between the maxillary-premaxillary } \\
\text { suture and the line that connects landmarks } 8 \text { and } 9\end{array}$ & $\begin{array}{l}\text { Maxillae, } \\
\text { premaxillae }\end{array}$ \\
\hline 11 & Zygomaxillare & $\begin{array}{l}\text { The zygomatico-maxillary suture at the root of the zygomatic } \\
\text { arch }\end{array}$ & Maxillae \\
\hline 12 & \multirow{2}{*}{ Nasospinale } & $\begin{array}{l}\text { The premaxillary suture at the inferior margin of the nasal } \\
\text { aperture in the midline }\end{array}$ & Premaxillae \\
\hline 13 & & $\begin{array}{l}\text { Points of intersection between the premaxillo-maxillary suture } \\
\text { and the line that connects landmarks } 11 \text { and } 12\end{array}$ & $\begin{array}{l}\text { Maxillae, } \\
\text { premaxillae }\end{array}$ \\
\hline \multicolumn{4}{|c|}{ Additional nasal bone's landmarks } \\
\hline $1 \mathrm{a}$ & Nasion & Intersection between the naso-frontal and the internasal sutures & Nasalia \\
\hline $2 \mathrm{a}$ & \multirow{3}{*}{ Infranasion } & $\begin{array}{l}\text { Intersection between the fronto-maxillary and the naso- } \\
\text { maxillary sutures }\end{array}$ & Nasalia \\
\hline $3 \mathrm{a}$ & & The midline of the nasal bones, the minimal width & Nasalia \\
\hline $4 \mathrm{a}$ & & $\begin{array}{l}\text { A point on the naso-maxillare suture at the minimal width of the } \\
\text { nasal bones }\end{array}$ & Nasalia \\
\hline $5 \mathrm{a}$ & Rhinion & Tip of the nasal bones in the midline & Nasalia \\
\hline $6 \mathrm{a}$ & Nasomaxillare & The most inferior point of the naso-premaxillary suture & Nasalia \\
\hline
\end{tabular}

performed for estimation of allometric contribution to growth and variation of the face. In order to further assess allometry and covariation among different configurations we have also calculated Spearman rank correlations between centroid sizes and PC1-2 values of the general configuration, the maxilla, the premaxilla and the nasal bones configurations (Tab. 3; see also Tab. 2 for sampling details). RV-coefficient (Klingenberg, 2009) as a measure of covariation between the sets of variables was used for estimation of association between the single bones' variation. We tested modularity hypotheses for the maxillae, the premaxillae and the nasal bone using MorphoJ 1.02 (Klingenberg, 2009, 2011). Dispersion analysis (analysis of variance, General Linear Model) was used for estimation of contribution of factors "SEX", "AGE" to variation of the PCs.

\section{Results}

Analysis of the general (whole face) configuration, 13 landmarks. PC1 from the analysis on the two species combined sample accounts for $71.8 \%$ of the total variation while PC2 explains just $6.0 \%$. The two species are separated along PC1 without an overlap
(Fig. 2A). Both sexes and age stages are well differentiated in $C$. torquatus. In contrast, in $P$. verus sex and age variation is insignificant. Analysis of variation for each species separately has shown that variation in $C$. torquatus is more structured than variation in P. verus. PC1 explains $58.3 \%$ of variation in C. torquatus. PC2 and PC 3 account for just a small portion of the total variation $-12.0 \%$ and $5.7 \%$ respectively. Factor loadings on the PCs in the two species are rather different. In the olive colobus PC1 accounts just for $26.6 \%$ of the total variation while PC2 takes only slightly less amount of variation, $21.9 \%$.

Analysis of variance shows that the two species are different in terms of amount of variation in PC scores that can be attributed to contribution from SEX and AGE factors. In C. torquatus PC1 explains a large portion of sexual dimorphism (contribution of factor SEX to PC1 is significant, $p<0.05)$. At the same time $\mathrm{PC} 2$ corresponds to age variation $(p<0.05)$. So, contribution of factors SEX and AGE is clearly structured in C. torquatus being separated between different PCs.

In $P$. verus significant contribution of factor AGE is found for $\mathrm{PC} 1-3(p<0.05)$, i.e. age variation in this species is distributed among the first three PCs. 
Table 2. The sample of $C$. torquatus and $P$. verus used in the study.

\begin{tabular}{|c|c|c|c|c|c|c|c|}
\hline Species & $\begin{array}{c}\text { Catalogue } \\
\text { no. }\end{array}$ & Sex & Age & Species & $\begin{array}{c}\text { Catalogue } \\
\text { no. }\end{array}$ & Sex & Age \\
\hline \multirow{25}{*}{$\begin{array}{c}\text { Cercocebus } \\
\text { torquatus }\end{array}$} & 13.4 & female & old adult & \multirow{16}{*}{$\begin{array}{c}\text { Procolobus } \\
\text { verus }\end{array}$} & 7.28 & female & juvenile \\
\hline & 13.1 & female & sub adult & & c7.13 & female & infant \\
\hline & 13.2 & female & adult & & c7.11 & female & juvenile \\
\hline & 13.3 & female & adult & & c7.15 & $?$ & immature \\
\hline & $13.5 \mathrm{a}$ & $?$ & adult? & & c7.14 & female & subadult \\
\hline & 13.8 & female & immature & & c7.12 & female & juvenile \\
\hline & 13.7 & $?$ & juvenile & & c7.16 & female & adult \\
\hline & 13.6 & $?$ & juvenile & & c7.17 & female & adult \\
\hline & 13.9 & female? & immature & & c7.18 & Male & adult \\
\hline & 13.18 & male & adult & & c7.19 & Female & adult \\
\hline & 13.19 & male? & adult & & c7.20 & male & adult \\
\hline & 13.23 & male & adult & & c7.21 & male & adult \\
\hline & $13.22 *$ & male & adult & & c7.22 & male & adult \\
\hline & 13.24 & male & adult & & c7.26 & female & adult \\
\hline & 13.25 & male & adult & & c7.23 & male & adult \\
\hline & 13.20 & male & subadult & & c7.24 & male & adult \\
\hline & 13.21 & male & adult & & & & \\
\hline & 13.38 & male & juvenile & & & & \\
\hline & 13.41 & $?$ & juvenile & & & & \\
\hline & 13.39 & male & juvenile & & & & \\
\hline & 13.36 & female & immature & & & & \\
\hline & 13.35 & female & immature & & & & \\
\hline & 13.34 & female & immature & & & & \\
\hline & 13.40 & $?$ & juvenile & & & & \\
\hline & 13.37 & male & juvenile & & & & \\
\hline
\end{tabular}

* bold font indicates specimens that were used for an additional analysis of the nasal bones.

PC1 describes increase in the facial prognathism, i.e. progression of the distal part of the maxilla and the premaxillae (Fig. 2A, insets). This finding just repeats the results of previous studies (Corner \& Richtsmeier, 1991; Richtsmeier et al., 1993; O’Higgins \& Jones, 1998; Collard \& O’Higgins, 2001; O’Higgins \& Collard, 2002; Cobb \& O'Higgins, 2004). According to both previous and our results, the PC1 scores have a high and significant correlation with centroid size (Spearman $\mathrm{R}=0.93 ; p<0.05$, Tab. 3 ) and hence corresponds to the main allometric trend ("linear growth model"; Fig. 3A). Exclusion of the neurocranial landmarks as well as the landmarks form the alveolar prosess and zygomatic region does not affect the results of the analysis: the largest part of variation is still accounted for the degree of prognathism which is far more prominent in C. torquatus.
Comparison of the analyses of configurations of the whole face and the maxilla. To describe the shape of the maxilla we used landmarks 2, 4, 5, 7, 8, 10, 11, 13 (Fig. 1A; Tab. 1). The variation trend in the maxilla is nearly identical to that of the general configuration. The analysis of data on the two species demonstrates that PC1 takes $71.0 \%$ of variation while PC2 accounts for $8.1 \%$. The configuration of plot in $\mathrm{PC} 1-\mathrm{PC} 2$ space (Fig. 2B) is almost identical to that of general landmark configuration and even many specimens hold the same place on the plot (compare the insets, Figs. 2A and 2B). Maxillae PC1 scores are highly correlated with centroid size $(\mathrm{R}=0.93 ; p<0.0001$; Tab. 3), i.e. PC1 explains the allometric variation (Fig. 3B).

Correlations between centroid sizes of the general configuration and the maxilla and PC1, PC2 scores (Tab. 3) are almost identical. It seems that the analysis

Figure 2. Principal components analysis of 13 (general) and 8 (the maxilla) landmark configuration. A — PC1 (horizontal axis) vs PC 2 (vertical axis) of the analysis of 13 landmarks configuration. Left inset - configuration representing PC1 $=-$ 0.18 and $\mathrm{PC} 2=0$, flat surface rendering; right inset - configuration representing $\mathrm{PC} 1=0.18$ and $\mathrm{PC} 2=0$, flat surface rendering. B - PC1 (horizontal axis) vs PC 2 (vertical axis) of the analysis of 8 landmarks configuration (the maxilla). Left inset - configuration representing $\mathrm{PC} 1=-0.18$ and $\mathrm{PC} 2=0$, flat surface rendering; right inset - configuration representing $\mathrm{PC} 1=0.18$ and $\mathrm{PC} 2=0$, flat surface rendering. Symbols: 1 - adult and subadult males of $C$. torquatus; 2 - adult and subadult females of $C$. torquatus; 3 - infant and juvenile males of $C$. torquatus; 4 - infant and juvenile females of $C$. torquatus; 5 - infant and juvenile specimens of C. torquatus, sex is unknown; 6 - adult and subadult males of $P$. verus; 7 adult and subadult females of $P$. verus; 8 - infant and juvenile females of $P$. verus; 9 - infant and juvenile specimens of $P$. verus, sex is unknown. 

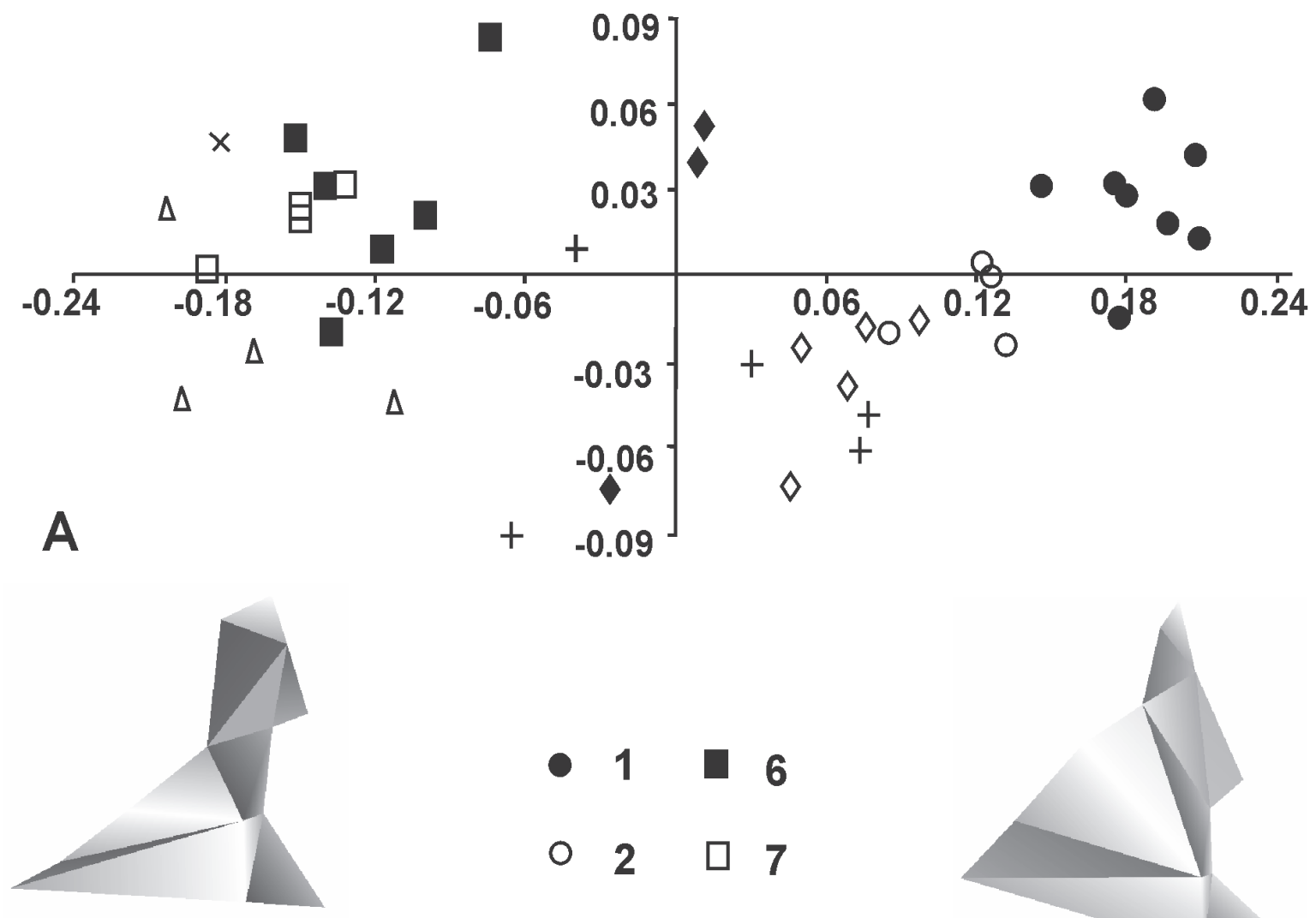

- 1 - 6

$\begin{array}{lll}\circ & 2 & 7\end{array}$

\begin{tabular}{l}
$-3 \Delta 8$ \\
\hline
\end{tabular}

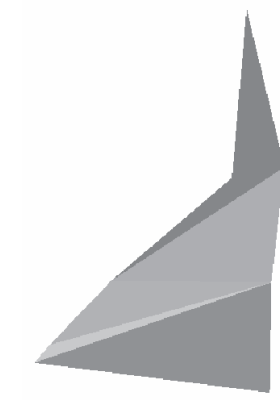

$\diamond 4 \times 9$

$+5$
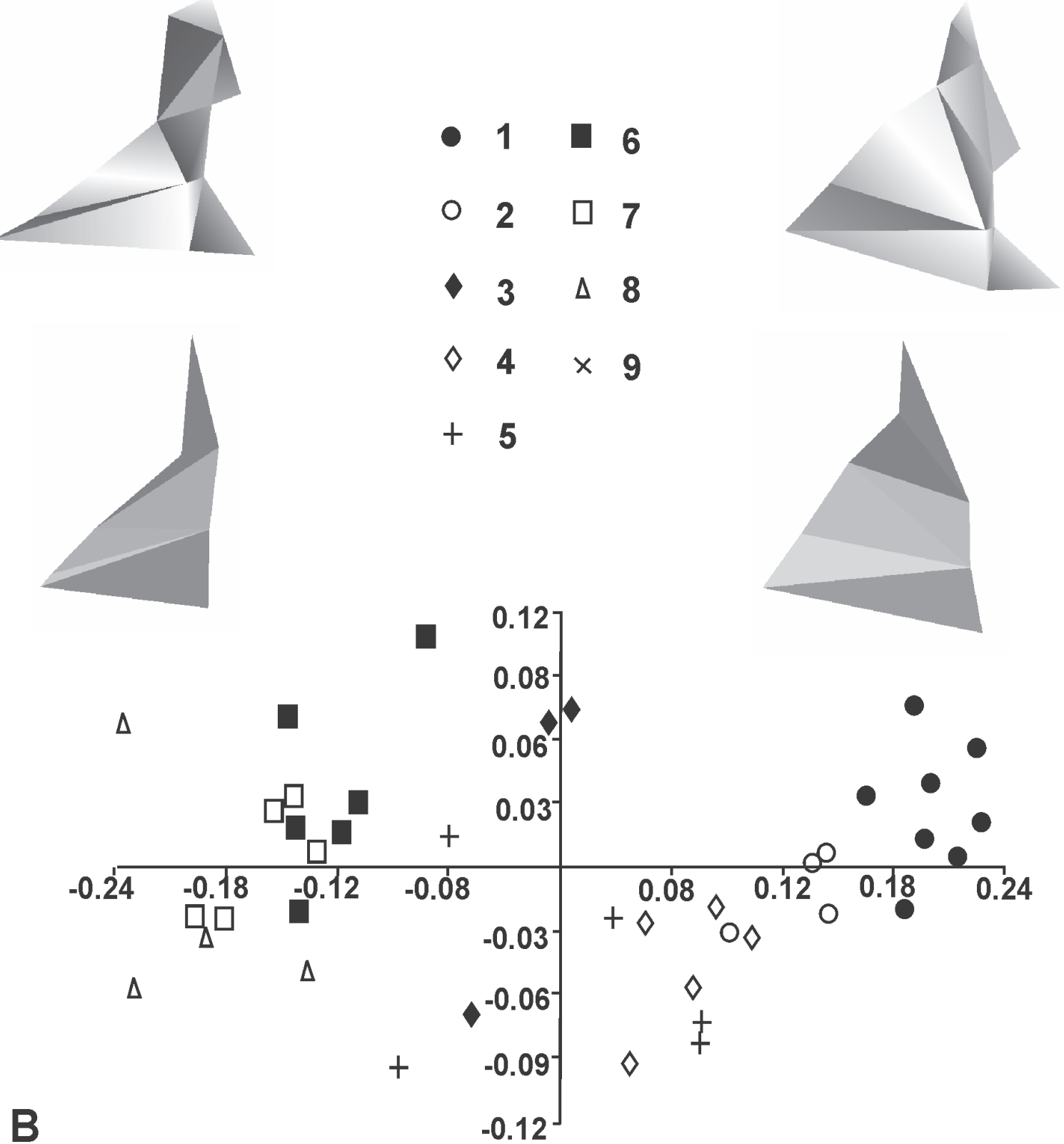
Table 3. Spearman's rank correlation coefficients between centroid size, PC1 and PC2 scores in the general configuration, and configurations of the maxilla, the premaxilla and the nasal bones (see Tab. 2 and "Materials and methods" section for sampling details).

\begin{tabular}{|c|c|c|c|c|c|c|c|c|c|c|c|c|}
\hline & 1 & 2 & 3 & 4 & 5 & 6 & 7 & 8 & 9 & $10 * *$ & $11 * *$ & $12 * *$ \\
\hline $\begin{array}{l}\text { 1. Centroid size, } \\
\text { general } \\
\text { configuration }\end{array}$ & & & & & & & & & & & & \\
\hline $\begin{array}{l}\text { 2. PC1, general } 1 \\
\text { configuration }\end{array}$ & $0.93 *$ & & & & & & & & & & & \\
\hline $\begin{array}{l}\text { 3. PC2, general } 1 \\
\text { configuration }\end{array}$ & 0.14 & 0.02 & & & & & & & & & & \\
\hline $\begin{array}{l}\text { 4. Centroid size, } \\
\text { maxillae }\end{array}$ & 0.99 & 0.92 & 0.10 & & & & & & & & & \\
\hline 5. PC1, maxillae & 0.94 & 0.99 & 0.04 & 0.93 & & & & & & & & \\
\hline 6. PC2, maxillae & 0.11 & 0.01 & 0.96 & 0.09 & 0.03 & & & & & & & \\
\hline $\begin{array}{l}\text { 7. Centroid size, } \\
\text { premaxillae }\end{array}$ & 0.86 & 0.73 & 0.47 & 0.84 & 0.75 & 0.38 & & & & & & \\
\hline $\begin{array}{l}\text { 8. } \mathrm{PC} 1, \\
\text { premaxillae }\end{array}$ & 0.37 & 0.44 & -0.44 & 0.35 & 0.43 & -0.49 & 0.08 & & & & & \\
\hline $\begin{array}{l}\text { 9. } \mathrm{PC} 2 \text {, } \\
\text { premaxillae }\end{array}$ & -0.17 & -0.29 & 0.32 & -0.19 & -0.28 & 0.28 & 0.09 & -0.02 & & & & \\
\hline $\begin{array}{l}\text { 10. Centroid size, } \\
\text { nasal bone** }\end{array}$ & 0.93 & 0.96 & -0.04 & 0.95 & 0.95 & 0.02 & 0.18 & 0.55 & -0.17 & & 0.89 & -0.23 \\
\hline $\begin{array}{l}\text { 11. PC1, nasal } \\
\text { bone** }\end{array}$ & 0.88 & 0.93 & 0.10 & 0.86 & 0.91 & 0.09 & 0.25 & 0.44 & -0.24 & 0.89 & & 0.07 \\
\hline $\begin{array}{l}\text { 12. PC2, nasal } \\
\text { bone** }\end{array}$ & -0.08 & -0.17 & 0.54 & -0.29 & -0.19 & 0.34 & 0.45 & -0.18 & 0.41 & -0.23 & 0.07 & \\
\hline
\end{tabular}

* significance level $p=0.05$.

** different sample size, see Tab. 2

of the general configuration of the facial skeleton is dominated by the maxilla variation whether it contains 31 (see O'Higgins, Jones, 1998 and Introduction) or 13 landmarks. Variation of the other facial bones is small comparing to variation of the maxilla. Reduction of landmarks configuration to 8 landmarks does not affect the result.

Analysis of maxillae modularity provides well interpretable results. The minimum covariation was detected between landmark sets comprising 2, 8, 10, 13 and 4, 5, 7, 11 (Fig. 6A). The second set might be associated with the eyeball growth (module "orbital", Cheverud, 1982). These landmarks almost do not change their relative position. Landmark 11 lies in the same plane with the orbital landmarks. Both landmark 5 and 11 belong to the zygomatic bone. Landmarks 8,10 and 13 are located on the fast growing facial region. They are markedly displaced forward during the growth away from landmarks $4,5,7$, but the distance among these landmarks itself remains unchanged. Landmark 2 moves up from landmarks 4, 5, 7 with growth in the frontomaxillary suture which takes place in the final stages of growth (O’Higgins \& Jones, 1998).

Variation of the premaxilla in comparison to variation of the general configuration. A comparison of the covariance matrices of the two species done using
Mantel-test suggests that the overall patterns of the maxilla's variation in $C$. torquatus and P.verus are different $(\mathrm{R}=0.2, p=0.8)$. In contrast, variation of the premaxilla in $C$. torquatus is similar to that of $P$. verus $(\mathrm{R}=0.91, p<0.01)$. Variation of the premaxilla is less structured in comparison to the maxilla. In the analysis of data on the two species combined PC1 takes 53.3\% of variation and PC2 accounts for $17.8 \%$ (Fig. 4A).

The two species overlap in the PC1/PC2 plot of the premaxilla shape (Fig. 4A). Specimens of juvenile and subadult mangabey's skulls lie within the range of the greatest values of PC1 (values $>0.08$, ellipse 1 on Fig. 4A). Adult mangabeys are dispersed in the range of the values of $\mathrm{PC} 1$ around zero (ellipse 2). Thus age axis of the mangabey has approximately the same direction as PC1. We can use PC1 as a proxy for the age vector for the premaxilla in C. torquatus. But note that $\mathrm{PC} 1$ scores are not correlated with centroid size (Spearman $\mathrm{R}=$ $0.08 ; p=0.62$, Fig. 4B).

Analysis of variance reveals that SEX and AGE factors do not contribute significantly to $\mathrm{PC} 1-3$ in $C$. torquatus, while factor AGE contributes significantly to $\mathrm{PC} 2$ in $P$. verus.

Scatterplot of the specimens in the space of PC1 and centroid size of the premaxilla (Fig. 4B) sharply differs from that of the maxilla. The premaxilla shape in imma- 

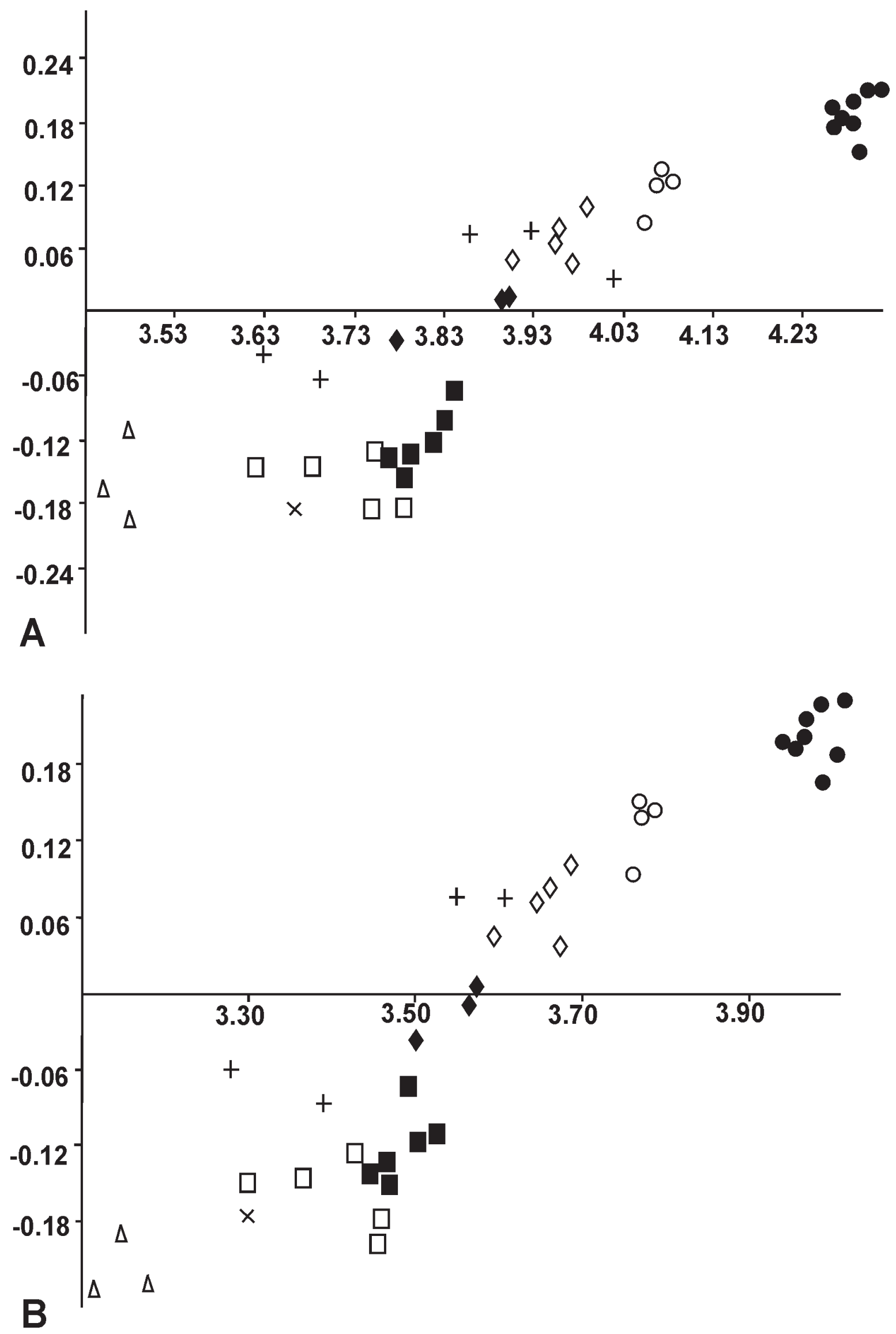


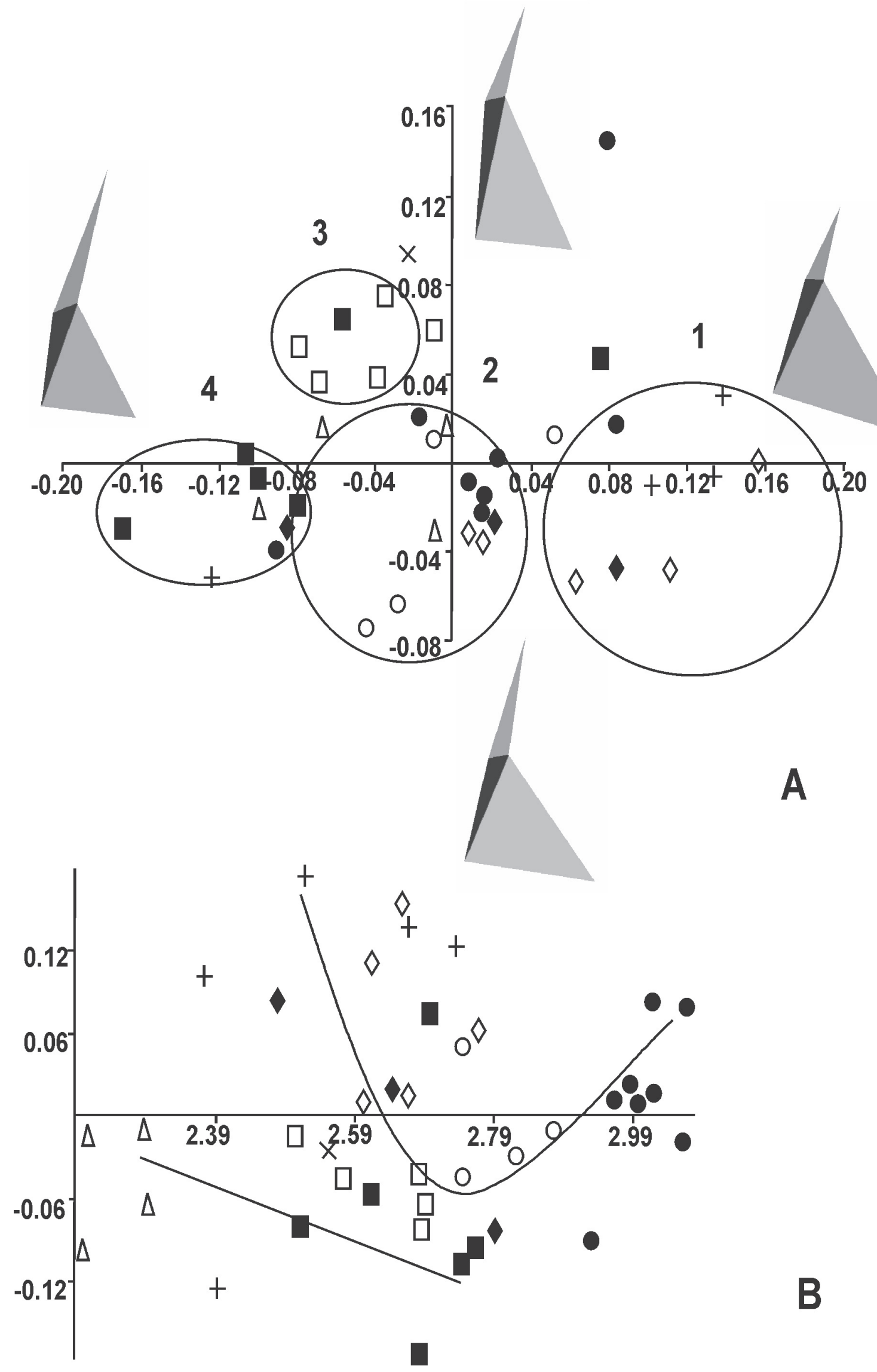


ture individuals strongly differs between the species despite their similarity in centroid size. At the same time the premaxilla of mature individuals of the two species converges in shape but not in size. Relationship between centroid size and PC1 for the premaxilla in $P$. verus looks like a linear relation. In contrast to that the relationship between centroid size and $\mathrm{PC} 1$ scores for the premaxilla in C. torquatus is obviously nonlinear (Fig. 4B).

As scores of PC1 of the premaxilla increase its lower part expands and extends (Fig. 4A, left and right insets). Greater values of PC2 scores of the premaxilla, which are characteristic for adult female (ellipse 3) but not male (ellipse 4) P. versus specimens, correspond to contraction of the frontal process and reduction in breadth and protrusion of the lower part of the premaxilla (Fig. 4A, top and bottom insets).

Significant correlation (Spearman $\mathrm{R}=0.86, p<$ 0.01 ) between centroid sizes of the premaxilla and the general configuration is observed (Tab. 3). Variation of PC1 of the premaxilla is weakly correlated with variation of the total facial size (Spearman $\mathrm{R}=0.37, p=$ 0.018 ).

$\mathrm{RV}$-coefficient between variation of the shape of the maxilla and the premaxilla is as high as 0.29 ( $p=$ 0.006 ). Analysis of modularity of the premaxilla reveals minimal covariation between two sets of landmarks: two landmarks from the lower part of the bone versus three points from the frontal process (Fig. 6B).

Variation of the nasal bones. To describe the nasal bones shape variation we applied a smaller sample: 8 individuals of $P$. verus and 11 C. torquatus (Tab. 2). Due to uneven sampling (see Materials and methods) we don't present ANOVA results here and the specific of the sample used for this part of the study should be born in mind when interpreting the results. PC1 accounts for $48.7 \%$ of variation, PC $2-26.0 \%$. The two species are separated by the nasal bones shape along the PC1. The intraspecific differentiation along the PC2 is also observed (Fig. 5A). The nasal bones' shape is narrow and elongated within the range of positive values of $\mathrm{PC} 1$. This is particularly typical for the superior part of the nasal bones. The nasal bones are relatively broad and short within the range of negative PC1 values (Fig. 5A, right and left insets). Thus PC1 represents strong interspecific differences of the shape of the nasal bones. Variation along PC2 corresponds to variation of the proximal part of the nasalia from short and broad to narrow and elongated form (Fig. 5A, top and bottom insets).

Significant correlation (Spearman $\mathrm{R}=0.89, p<$ 0.0001 ) between centroid size of the nasal bone and PC1 scores is observed, but this correlation is slightly lower than that of the maxilla (Tab. 3). Correlation between PC2 scores and centroid size of the nasals bone fails to reach significance level. Variation of size of the nasal bone seems to be more pronounced in $C$. torquatus compared to variation in shape while the opposite is the truth in P. verus (Fig. 5B).

PC1 scores of the nasal bones are strongly correlated with variation of the total facial size (Spearman $\mathrm{R}=$ 0.93, $p<0.05$; Tab. 3). The situation is different when the two species are analysed separately. The correlation coefficient is $0.96(p<0.05)$ in $C$. torquatus but only $0.62(p<0.05)$ in $P$. verus.

A modularity hypothesis for the nasal bones applied here is based on the concept of differences between the growth processes in the proximal and distal parts of the nasal bones (Fig. 6C). The proximal part grows preand perinatally (Sysak, 1960; Richtsmeier et al., 1993; Sonek et al., 2003; Marimoto et al., 2008; Mogra et al., 2010), but the distal part grows in the later ontogenetic stages accordingly to the general facial growth (Enlow, 1966; Richtsmeier et al., 1993; O’Higgins \& Jones, 1998; O’Higgins \& Collard, 2002). Landmarks 1, 2, 3, and 4 were included into the first module and landmarks 5 and 6 into the second one. A test of modularity has confirmed the proposed hypothesis. We thus conclude that the upper and lower parts of the nasal bones vary to a substantial degree independently.

PLS analysis done in MorphoJ has shown that the nasal bone variation is not very strongly correlated with variation of both the maxilla $(\mathrm{RV}=0.49, p=0.0294)$ and the premaxilla $(\mathrm{RV}=0.45, p=0.0523$, non significant).

\section{Discussion}

The results of embryological (Latham, 1970; Sonek et al., 2003; Depew et al., 2005; Marimoto et al., 2008; Mogra et al., 2010), functional anatomical and abundant morphometric (Bunak, 1960; Sysak, 1960; Enlow, 1966; Mooney \& Siegel, 1986; Richtsmeier et al., 1993; O’Higgins \& Jones, 1998; O’Higgins \& Collard, 2001; Holton et al., 2010, 2011) studies clearly demonstrate a certain degree of independence of the growth processes of the main bones forming the middle part of the upper facial skeleton: the maxilla, the premaxilla and the nasalia. The results of present study are in very good agreement with those data and demonstrate that the analysis of single bones morphology and growth dynamics could potentially provide a lot of useful additional information that may be of interest from both functional anatomical and systematic points of view. Such an approach is more effective if structures experiencing direct and strong mechanical influence (the molars, the alveolar process, the zygomatic arch) are excluded from a landmark configuration. It is also note-

Figure 4. Principal components analysis of the premaxilla configuration: A - PC1 (horizontal axis) vs PC 2 (vertical axis). Left inset - configuration representing $\mathrm{PC} 1=-0.16$ and $\mathrm{PC} 2=0$; right inset - configuration representing $\mathrm{PC} 1=0.16$ and $\mathrm{PC} 2=0$; bottom inset - configuration representing $\mathrm{PC} 1=0$ and $\mathrm{PC} 2=-0.06$; top inset - configuration representing $\mathrm{PC} 1=$ 0 and PC2 $=0.12$ (flat surface rendering); B - plot of PC1 (vertical axis) from PCA vs ln centroid size (horizontal axis). See text for details. Symbols - see legend to Fig. 2. 


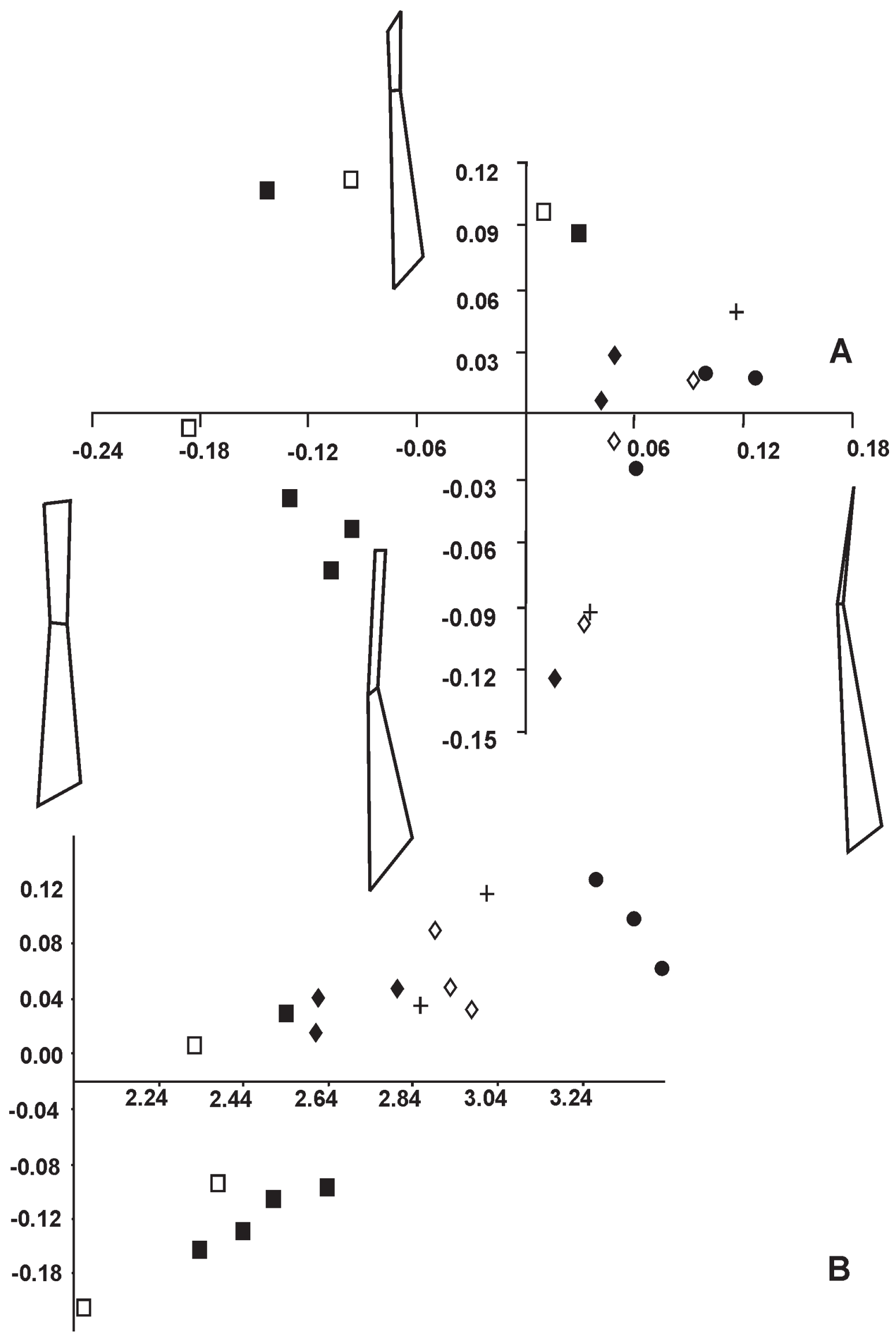




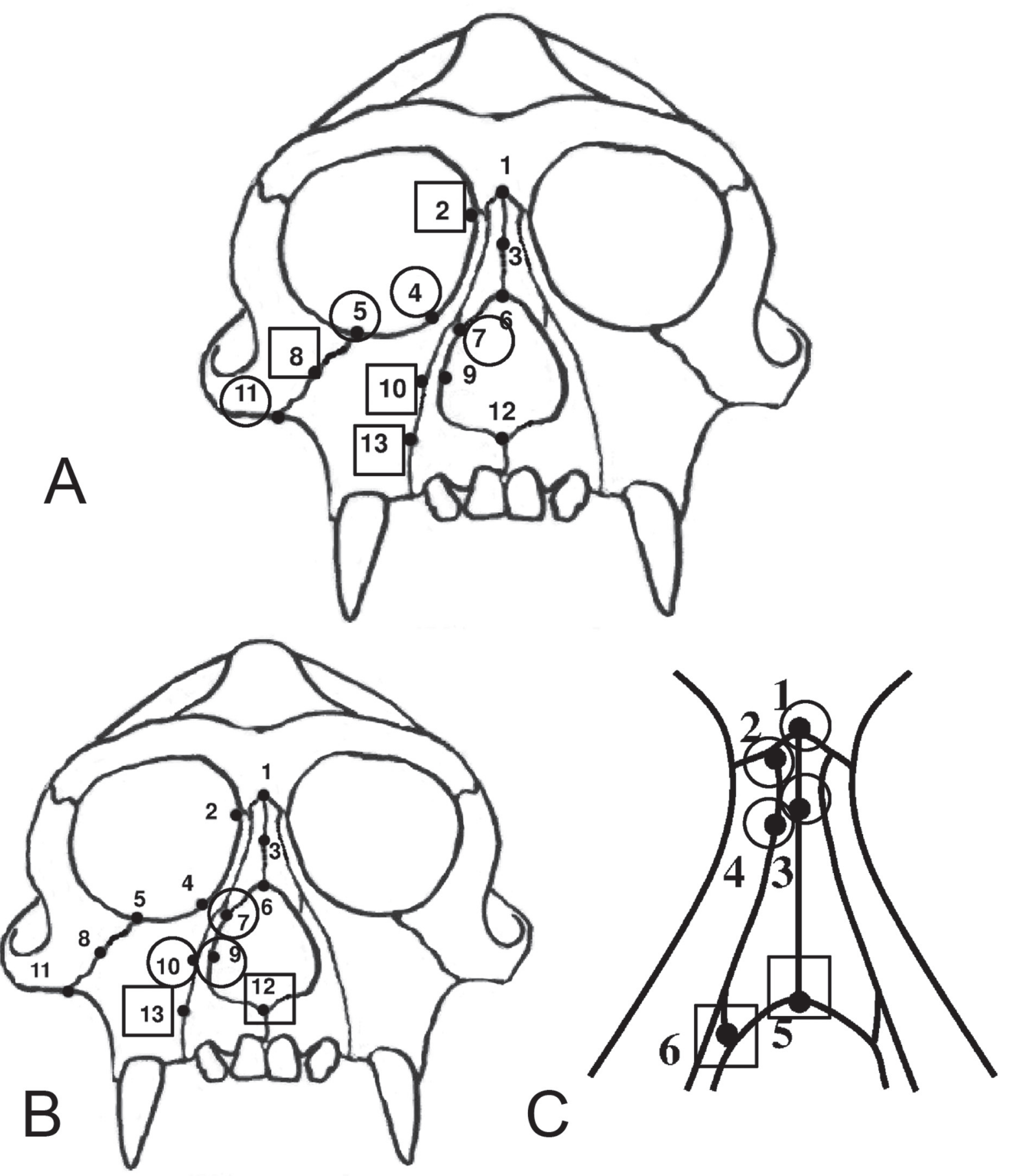

Figure 6. Modularity hypotheses testing: A - the maxilla. The minimal covariation was detected between landmark sets 2,8 , 10, 13 (squares) and 4, 5, 7, 11 (circles); B - the premaxilla. The minimal covariation was detected between landmark sets 12 and 13 (squares) and 7, 9, 10 (circles); $\mathrm{C}$ - the nasal bone. 2- and 4-landmarks sets which have minimal covariation. See text for details and Fig. 1 and Tab. 1 for definition of the landmarks.

Figure 5. Principal components analysis of the nasal bone configuration. A - PC1 (horizontal axis) vs PC 2 (vertical axis). Left inset - configuration representing $\mathrm{PC} 1=-0.14$ and $\mathrm{PC} 2=0$; right inset - configuration representing $\mathrm{PC} 1=0.11$ and $\mathrm{PC} 2=0$; bottom inset - configuration representing $\mathrm{PC} 1=0$ and $\mathrm{PC} 2=-0.12$; top inset - configuration representing $\mathrm{PC} 1=$ 0 and $\mathrm{PC} 2=0.10$ (flat surface rendering); $\mathrm{B}$ - plot of PC1 (vertical axis) from PCA vs ln centroid size (horizontal axis). Symbols - see legend to Fig. 2. 
worthy that visualized configurations of single bones can be better understood by a reader and more easily interpreted since such configurations are far less complex comparing to a configuration of the whole face. When looking at the later observer's attention gets involuntary concentrated on the most noticeable morphological phenomena. Such as for example intensive growth of the maxilla in vertical and antero-posterior directions which is common for all the primates even for Homo sapiens and Macaca (Enlow, 1966). Dealing with single bone's morphology could provide information on its "localized" growth events (Enlow, 1966). Single bones cannot be considered as modules but each bone can comprise two or more distinctive functional or/and developmental units which wouldn't be identified without a closer look at the bone's morphology (Enlow, 1966; Klingenberg et al., 2004).

It does not contradict to views on the facial skeleton as a tightly integrated structure. The integration is a result of general somatic growth factors' influence, biomechanical loadings and simple topographic correlations with other bones. One bony element can serve as a matrix for other being a source of quasi-static strain particularly if the two elements are connected with an interdigitated suture (Kopher \& Mao, 2003; Herring, 2008). Remodelling maps of different species show that resorptive and depository fields do not coincide with bones' boundaries also argue against "independent' growth of single bones (Enlow, 1966; O'Higgins $\&$ Jones, 1998). High correlations of centroid sizes of the maxilla, the premaxilla and the nasal bones found in the present study again confirm a high level of integration in the facial skeleton.

But despite this integration the nasal bones and the premaxilla which do not share first branchial arch origin with the maxilla obviously retain in the adults some features of shape formed during the prenatal phase of growth. Thus careful examination of their morphology and growth could give us additional data on early growth events which is known to be in many cases crucial for emergence of between taxa differences in ontogeny (Franciscus, 1995; O’Higgins et al., 2001). Such differences forms prior to beginning of intensive hormonal and mechanical stimuli activity and thus they are under a stricter genetic control so their morphological variation may be more suitable for phylogenetic researches (Cardini \& Elton, 2008a). It can be also seen as an example of evolutionary modules that serve for different functions and are due to this controlled by different genes at different stages of ontogeny (Wagner \& Altenberg, 1996). During postnatal growth the shape of each of these bones is substantially modified so research of ontogenetic samples is often more informative than just comparing adult morphology (O'Higgins \& Collard, 2002).

An answer to the old question "natal morphology versus ontogenetic scaling" (O'Higgins et al., 2001; Ackermann \& Krovitz, 2002; Vidarsdóttir et al., 2002; Cobb \& O'Higgins, 2004) will be different depending on what part of the facial skeleton is discussed. Postna- tal scaling which can be successfully described by the "linear growth model" (O'Higgins \& Jones, 1998; O’Higgins et al., 2001; O’Higgins \& Collard, 2002) dominates in growth of the maxilla while most specific morphological features of the premaxilla forms prenatally. The proximal and distal parts of the nasal bones seem to behave like relatively independent units. The former attains its nearly adult shape and size very early in ontogeny, probably in the second trimester of gestation (Sonek et al., 2003; Mogra et al., 2010) and the later grows predominantly in the postnatal period in a strong dependence on growth of the maxilla (Richtsmeier et al., 1993; O’Higgins \& Jones, 1998).

This fairly complicated picture of interdependent growth processes also means that while a single bone's morphology is worth noting it should be only investigated in the context of the adjacent bones morphology otherwise some facts cannot be explained (Lang \& Baumeister, 1982; Hwang et al., 2005).

Since relative importance of different functions of the facial skeleton as well as a set of growth factors (FGF and BMP systems versus growth hormone and steroids) change dramatically between the gestation, infancy and adolescence it becomes difficult to outline some "constant" modules which hold its identity during the whole period of growth. Thus it might be a perspective approach to search for modules at each particular stage of ontogeny according to its biologically valid periodization. The premaxilla for instance can be considered as a module in the pre- and perinatal period but later it becomes a part of another module a "core" of which is actively growing maxilla ("muzzle"). Both this stages of the premaxilla's growth leave traces in the definitive morphology of this bone. Trends in the nasal bones are fairly similar: their growth seems to be autonomous during the gestation and probably has its own growth factors but later in ontogeny follows the maxilla growth. Finally, the maxilla (probably excepting frontal process) does not play a substantial role in determining the foetal and early infant primate facial skeleton architecture but becomes a "promoter" of postnatal growth of the face particularly in long-faced animals.

Comparison of the analyses of the whole face and the maxilla configurations. When comparing the whole face and the maxilla configurations (Figs. 2A, B) the most prominent morphological change attracting attention in the both cases is elongation of the muzzle. This phenomenon seems to be the major and the most dynamic event during postnatal growth but in the same time it can "eclipse" many subtle but not less important aspects of the facial skeleton variability. As a matter of fact the results are very similar in analyses of a comprehensive configuration of 31 landmarks including points from the anterior neurocranium and the zygomatic area (O’Higgins \& Jones, 1998; O’Higgins et al., 2001), 13 landmarks excluding the neurocranium and the zygomatic area and, finally, 8 landmarks which represent the anterior part of the maxilla only. In all these cases the first PCs accounts for enormous part of the total varia- 
tion (not less than 70\%) and describes essentially the same morphological features. This trend is particularly strong in the cases when specimens of a long-faced animal species are included in the analysis (Collard \& O’Higgins, 2001; O’Higgins \& Collard, 2002; Cobb \& O’Higgins, 2004; Cardini \& Elton, 2008a). According to Hallgrimsson (2004) a murine strain with elongated (i.e. normal) face demonstrated a craniofacial variation pattern which was closer to that in macaques (also longfaced animal) than to another murine strain with the facial skeleton shortened due to a mutation.

In the present study when the "general" configuration (13 landmarks) is analysed separately for the two species they show completely different results. In Cercocebus PC 1 again dominates while in Procolobus variation is far less "structured" or in the other words it's evenly distributed among the first three PCs. This observation completely confirms the results of the previous study where $C$. torquatus were compared with another orthognathic species, C. apella (O'Higgins et al., 2001). The completely identical results of the whole face and maxilla configurations analyses found in our study (Figs. 2, 3; Tab. 3) suggest that rapid postnatal growth of the muzzle depends mostly on the maxilla's growth while the two other bones play a "subordinate" role. For interpretation of these results it may be useful to remember "branchial" origin of the maxilla which makes it ontogenetically closer to the postcranial skeletal elements. Though like in all cranial structures HOX genes are not active in the jaws, the latter have its own segmentation gene cluster, DLX. It is placed close to HOX cluster in the genome and works in the similar to HOX way (Depew et al., 2005). High correlation of growth processes of both jaws with general somatic growth is very well known (Sperber, 2001; Bulygina et al., 2006; Funatsu et al., 2006) as well as the correlation of the length of the muzzle with body size in close Old World monkey species (Collard \& O'Higgins, 2001).

In the same time it seems to be the case that elongation of the facial skeleton can lead to a decrease of bite force production capability, particularly at the anterior teeth (Koyabu \& Endo, 2009; McGraw et al., 2011). Thus elongation of the muzzle in $C$. torquatus which feed on very hard food can hardly be considered as an adaptive feature but rather as a result of a general body size increase.

Morphological variation of the premaxilla and its possible adaptive and ontogenetic explanation. Evidences for a specific growth pattern of the premaxilla comparing to the maxilla is clear in all the statistical analyses carried out in this study. Centroid sizes of the two bones are strongly correlated but neither PC1 nor PC2 of the premaxilla analysis is correlated with its own centroid size (Tab. 3). Regression analysis (GLM) has demonstrated that SEX and AGE factors do not contribute to PC1 in both species (even in long-faced $C$. torquatus) and it means that the most important morphological features of the bone described by these PCs form early in ontogeny before those factors start acting.
Probably the most interesting finding is the postnatal changes in the shape of the premaxilla in C. torquatus which demonstrate a kind of curvilinear correlation with centroid size of the bone (Fig. 4B). Modularity hypothesis testing seems to further support this finding showing that the inferior part of the premaxilla (excluding alveolar process) and its frontal process can be considered as relatively independent units (Fig. 6B). Speculatively it can be explained in the following way.

The inferior part of the premaxilla in infant and young mangabeys is expanded and anteriorly shifted while the frontal process is relatively short. It might be an adaptation for accommodation of large incisors (a characteristic trait of all mangabeys) and a way to increase of the whole bone "robustness" before beginning of the extreme masticatory loadings which start in this animals during the first year of life (McGraw, 2011). So in this case masticatory adaptation might express itself not as a result of direct stimulation of bone growth by cyclic strains (Kopher \& Mao, 2003; Curtis et al., 2008; Herring, 2008) but prior to this stimulation as a preparation for it. The masticatory muscles do not influence growth during prenatal and early postnatal periods but the nasal septum is very active at that time as a source of quasi-static stress to adjacent bones (Latham, 1970; Mooney \& Siegel, 1986). Reaction of the bone to this stimulus may depend a lot on its intrinsic genetically determined capacity to growth. It fits very well with Cheverud's data (1982) according to which the lower breadth of the premaxilla is among very few facial dimensions with high narrow-sense heritability.

Then increase in the lower breadth of the premaxilla slows down while its frontal process begins stretching following the growing maxilla to which it is rigidly mounted by a suture. Thus the whole structure becomes more similar to the pattern of $P$. verus where disproportion of the two parts of the premaxilla is not so pronounced. Intensive antero-inferior growth of the muzzle in the adult male Cercocebus certainly involves the premaxilla - its lower part again increases in size. Thus relative length of the frontal process again decreases. Superficially such morphology reminds the juvenile pattern. The growth trajectory of the C. torcuatus premaxilla can also serve as an example of sexual differences which are not directly related to size differences and occur in the final stages of growth (O'Higgins \& Jones, 1998; O’Higgins et al., 2001; O'Higgins \& Collard, 2002).

Interestingly the premaxilla morphology is more similar in the adults of both species than in subadults due to great differences between the later. Such sharp interspecific differences in the earliest stages of postnatal growth were noticed by Richtsmeier et al. (1993). In humans a population-specific pattern of the nasal aperture and the anterior nasal spine also forms mostly prenatally (Latham, 1970; Mooney \& Siegel, 1986; Franciscus, 1995) so even very young children from morphologically distinct populations can be correctly 
statistically discriminated (Vidarsdóttir et al., 2002). It may suggest that the "traction model" (Latham, 1970; Mooney \& Siegel, 1986) that describes links between growth of the nasal septum and the premaxilla through the septo-premaxillary ligament is a universal ontogenetic mechanism in many primate species (see also Schultz, 1963). Thus formation of the adaptive features of the premaxilla morphology may be shifted to the earlier stages of growth to provide for a strict genetic control of growth with minimal biasing influence from common growth factors and biomechanical stimuli.

The nasal bones variation. Substantial inter- and intraspecific variation of the nasal bones in the primates is well established (Schultz, 1963). In Homo sapiens morphology of the nasalia is also extremely variable and plays an important role in the classification and comparing populations in both craniological and living people researches (Martin, 1928; Woo \& Morant, 1934; Alexeev, 1969, 1974; Howells, 1989; Roseman \& Weaver, 2004). Despite this there are very few studies devoted to comprehensive investigation of the nasal bones' variation and growth, factors influencing its growth and interplay with the other bones' growth (Enlow, 1966; Lang \& Baumeister, 1982; Hwang et al., 2005). Thus the results of the present study may be of some interest despite of using a small and biased sample (see Material and methods).

First of all, the results of all the statistical analyses (PCA, PLS, modularity hypothesis testing) have confirmed a priory hypothesis of relatively independent variation in the upper and lower parts of the bone. Like the premaxilla, the nasal bones grow rapidly prenatally when its proximal part almost attains adult size (Sysak, 1960; Sonek et al., 2003; Mogra et al., 2010). But in contrast to the premaxilla it does not seem to have a substantial adaptive value. Due to these facts the proximal part of the nasalia fits to "good module" criteria (Cardini \& Elton, 2008a): it grows under strict genetic control while being free from strong functional influences. It is likely that a broader implementation of the nasal bone morphology in the primate craniometrical studies might provide some valuable additional information for phylogenetic reconstructions.

The nasal bone growth dynamic completely changes in postnatal ontogeny. Being rigidly attached to the maxilla by a suture it elongates accordingly to the maxilla elongation. This is more prominent in a longfaced species $C$. torquatus while the nasal bones of $P$. verus seem to be more "independent". Similar tendencies have been described in many previous researches (Richtsmeier et al., 1993; O’Higgins \& Jones, 1998; Cardini \& Elton, 2008b). But this "maxilla-dependent" growth is predominantly a feature of the distal part of the bone while the proximal part could keep its original size and shape relatively unchanged.

ACKNOWLEDGEMENTS. This research was supported by grants from the Wenner-Gren Foundation, The Royal Society of the Great Britain (grant JP100455), President Grant for Government Support of Young Russian Scientists (grant MK-1681.2012.4) and Russian Foundation for Basic Research (grants 12-06-00036-a and 12-04-31013). The authors would like to acknowledge Prof. Shara E. Bailey (New York University), Prof. Paul O'Higgins (The University of York), Dr. Vitaly M. Kharitonov and Dr. Ekaterina Yu. Bulygina (Institute and Museum of Anthropology, Moscow State University), and two anonymous reviewers who have helped a lot to improve this manuscript.

\section{References}

Abzhanov A., Protas M., Grant B.R., Grant P.R. \& Tabin C.J. 2004. Bmp4 and morphological variation of beaks in Darwin's finches // Science. Vol.305. P.1462-1465.

Ackermann R.R. \& Krovitz G.E. 2002. Common patterns of facial ontogeny in the hominid lineage // Anatomical Record. Vol.269. P.142-147.

Adams D.C., Cardini A., Monteiro L.R., O’Higgins P. \& Rohlf F.J. 2011. Morphometrics and phylogenetics: Principal components of shape from cranial modules are neither appropriate nor effective cladistic characters // Journal of Human Evolution. Vol.60. P.240-243.

Alexeev V.P. 1969. [Origin of the Peoples of the Eastern Europe]. Moskva: Nauka. 328 p. [in Russian].

Alexeev V.P. 1974. [Origin of the Peoples of the Caucasus]. Moskva: Nauka. 315 p. [in Russian].

Bastir M., Rosas A. \& O'Higgins P. 2006. Craniofacial levels and the morphological maturation of the human skull // Journal of Anatomy. Vol.209. No.5. P.637-654.

Bjork A. 1968. The use of metallic implants in the study of facial growth in children: method and application // American Journal of Physical Anthropology. Vol.29. P.243254.

Bulygina E., Mitteroecker P. \& Aiello L. 2006. Ontogeny of facial dimorphism and patterns of individual development within one human population // American Journal of Physical Anthropology. Vol.131. P.432-443.

Bunak V.V. 1960. [The facial skeleton and the factors determining variation of its morphology] // Proceedings of the Institute of Ethnography, New Series. T.50. P.84-152 [in Russian].

Cardini A. \& Elton S. 2008a. Does the skull carry a phylogenetic signal? Evolution and modularity in the guenons // Biological Journal of the Linnean Society. Vol.93. P.813834.

Cardini A. \& Elton S. 2008b. Variation in guenon skulls (I): species divergence, ecological and genetic differences // Journal of Human Evolution. Vol.54. P.615-637.

Carey J.W. \& Steegmann A.T. 1981. Human nasal protrusion, latitude, and climate // American Journal of Physical Anthropology. Vol.56. No.3. P.313-319.

Cheverud J.M. 1982. Phenotypic, genetic, and environmental morphological integration in the cranium // Evolution. Vol.36. No.3. P.499-516.

Churchill S.E., Shackelford L.L., Georgi J.N. \& Black M.T. 2004. Morphological variation and airflow dynamics in the human nose // American Journal of Human Biology. Vol.16. P.625-638.

Cobb S.N. \& O'Higgins P. 2004. Hominins do not share a common postnatal facial ontogenetic shape trajectory // Journal of Experimental Zoology, Part B: Molecular and Developmental Evolution. Vol.302. P.302-321. 
Collard M. \& O'Higgins P. 2001. Ontogeny and homoplasy in the papionin monkey face // Evolution \& Development. Vol.3. No.5. P.322-331.

Corner B.D. \& Richtsmeier J.T. 1991. Morphometric analysis of craniofacial growth in Cebus apella // American Journal of Physical Anthropology. Vol.84. P.323-342.

Creuzet S., Couly G. \& Le Douarin N.M. 2005. Patterning the neural crest derivatives during development of the vertebrate head: insights from avian studies // Journal of Anatomy. Vol.207. P.447-459.

Curtis N., Kupczik K., O’Higgins P., Moazen M. \& Fagan M. 2008. Predicting skull loading: applying multibody dynamics analysis to a macaque skull // The Anatomical Record. Vol.291. P.491-501.

Davies G. \& Oates J. (eds.). 1995. Colobine Monkeys: Their Ecology, Behaviour and Evolution. Cambridge: Cambridge University Press. $432 \mathrm{p}$.

Depew M.J., Compagnucci C. \& Griffin J. 2008. Suture neontology and paleontology: the bases for where, when and how boundaries between bones have been established and have evolved // Rice D.P. (ed.). Craniofacial Sutures: Development, Disease, and Treatment. Frontiers of Oral Biology, Basel. Vol.12. P.57-78.

Depew M.J., Simpson C.A., Morasso M. \& Rubenstein J.L.R. 2005. Reassessing the Dlx code: the genetic regulation of branchial arch skeletal pattern and development // Journal of Anatomy. Vol.207. P.501-561.

Enlow D.H. 1966. A comparative study of facial growth in Homo and Macaca // American Journal of Physical Anthropology. Vol.24. P.293-308.

Enlow D.H. 1975. Handbook of Facial Growth. Philadelphia: W.B. Saunders Company. 423 p.

Franciscus R.G. 1995. Later Pleistocene Nasofacial Variation in Western Eurasia and Africa and Modern Human Origins. PhD Thesis, University of New Mexico. 377 p.

Funatsu M., Sato K. \& Mitani H. 2006. Effects of growth hormone on craniofacial growth // Angle Orthodontist. Vol.76 No.6. P.970-977.

Glanville E.V. 1969. Nasal shape, prognathism and adaptation in man // American Journal of Physical Anthropology. Vol.30. P.29-38.

Hallgrimsson B., Willmore K., Dorval C. \& Cooper D.M.L. 2004. Craniofacial variability and modularity in macaques and mice // Journal of Experimental Zoology. Part B: Molecular and Developmental Evolution. Vol.302. P. 207-225.

Hammer Ø., Harper D.A.T. \& Ryan P.D. 2001. PAST Paleontological Statistics Software Package for Education and Data Analysis.

Herring S.W. 2008. Mechanical influences on suture development and patency // Rice D.P. (ed.). Craniofacial Sutures: Development, Disease, and Treatment. Frontiers of Oral Biology, Basel. Vol.12. P.41-56.

Holton N.E., Franciscus R.G., Marshall S.D., Southard T.E. \& Nieves M.A. 2011. Nasal septal and premaxillary developmental integration: implications for facial reduction in Homo // Anatomical Record. Vol.294. P.68-78.

Holton N.E., Franciscus R.G., Nieves M.A., Marshall S.D., Reimer S.B., Southard T.E., Keller J.C. \& Maddux S.D. 2010. Sutural growth restriction and modern human fa- cial evolution: an experimental study in a pig model // Journal of Anatomy. Vol.216. P.48-61.

Howells W.W. 1989. Skull shapes and the map // Peabody Museum Paper. Vol.79. P.1-189.

Hwang T.-S., Song J., Yoon H., Cho B.-P. \& Kang H.-S. 2005. Morphometry of the nasal bones and piriform apertures in Koreans // Annals of Anatomy. Vol.187. P.411-414.

Klingenberg C.P., Leamy L.J. \& Cheverud J.M. 2004. Integration and modularity of quantitative trait locus effects on geometric shape in the mouse mandible // Genetics. Vol.166. P.1909-1921.

Klingenberg C. P. 2009. Morphometric integration and modularity in configurations of landmarks: tools for evaluating a priori hypotheses // Evolution \& Development. Vol.11. P.405-421.

Klingenberg C.P. 2011. MorphoJ: an integrated software package for geometric morphometrics // Molecular Ecology Resources. Vol.11. P.353-357.

Kopher R.A. \& Mao J.J. 2003. Sutural growth modulated by the oscillatory component of micromechanical strain // Journal of Bone and Mineral Research. Vol.18. P.521528.

Koyabu D.B. \& Endo H. 2009. Craniofacial variation and dietary adaptations of African colobines // Journal of Human Evolution Vol.56. P.525-536.

Lang J. \& Baumeister R. 1982. On postnatal growth of the nasal cavity // Gegenbaurs Morphologisches Jahrbuch. Vol.128. P.354-393.

Latham R.A. 1970. Maxillary development and growth: the septo-premaxillary ligament // Journal of Anatomy. Vol.107. No.3. P.471-478.

Lieberman D.E., Ross C. \& Ravosa M.J. 2000. The primate cranial base: ontogeny, function, and integration // Yearbook of Physical Anthropology. Vol.43. P.117-169.

Martin R. 1928. Lehrbuch der Anthropologie in Systematischer Darstellung. Vol.2: Kraniologie, Osteologie. Jena: Gustav Fischer. 604 S.

Martinez Abadias N. 2007. Evolutionary patterns of the human skull. A quantitative genetic analysis of craniofacial phenotypic variation. $\mathrm{PhD}$ thesis. Universitat de Barcelona. 256 p.

McGraw W.S., Vick A.E. \& Daegling D.J. 2011. Sex and age differences in the diet and ingestive behaviors of sooty mangabeys (Cercocebus atys) in the Tai Forest, Ivory Coast // American Journal of Physical Anthropology. Vol.144. P.140-153.

Mogra R., Schluter P.J., Ogle R.F., O'Connel J., Fortus L. \& Hyett J.A. 2010. A prospective cross-sectional study to define racial variation in fetal nasal bone length through ultrasound assessment at 18-20 weeks' gestation // Australian and New Zealand Journal of Obstetrics and Gynaecology. Vol.50. P.528-533.

Mooney M.P. \& Siegel M.I. 1986. Developmental relationship between premaxillary-maxillary suture patency and anterior nasal spine morphology // Cleft Palate Journal. Vol.23. P.101-107.

Morimoto N., Ogihara N., Katayama K. \& Shiota K. 2008. Three-dimensional ontogenetic shape changes in the human cranium during the fetal period // Journal of Anatomy. Vol.212. P.627-635. 
Moss M.L. \& Young R.W. 1960. A functional approach to craniology // American Journal of Physical Anthropology. Vol.18. P.281-292.

O'Higgins P., Chadfield P. \& Jones N. 2001. Facial growth and the ontogeny of morphological variation within and between the primates Cebus apella and Cercocebus torquatus // Journal of Zoology, London. Vol.254. P.337357.

O’Higgins P. \& Collard M. 2002. Sexual dimorphism and facial growth in papionin monkeys // Journal of Zoology, London. Vol.257. P.255-272.

O'Higgins P. \& Jones N. 1998. Facial growth in Cercocebus torquatus: an application of three-dimensional geometric morphometric techniques to the study of morphological variation // Journal of Anatomy. Vol.193. P.251-272.

Oxnard C. \& O'Higgins P. 2009. Biology clearly needs morphometrics. Does morphometrics need biology? // Biological Theory: Integrating Development, Evolution and Cognition. Vol.4. No.1. P.84-97.

Ponce de Leon M. \& Zollikofer C. 2001. Neanderthal cranial ontogeny and its implications for late hominid diversity // Nature. Vol.412. P.534-538.

Rice D.P. 2008. Developmental anatomy of craniofacial sutures // Rice D.P. (ed.). Craniofacial Sutures: Development, Disease, and Treatment. Frontiers of Oral Biology, Basel. Vol.12. P.1-21.

Richmond B.G., Wright B.W., Grosse I., Dechow P.C., Ross C.F., Spencer M.A. \& Strait D.S. 2005. Finite element analysis in functional morphology // Anatomical Record. Vol.283A. P.259-274.

Richtsmeier J.T., Corner B.D., Grausz H.M., Cheverud J.M. \& Dahaney S.E. 1993. The role of post natal growth in the production of facial morphology // Systematic Biology. Vol.42. P.307-330.

Roseman C.C. \& Weaver T.D. 2004. Multivariate apportionment of global human craniometric diversity // American Journal of Physical Anthropology. Vol.125. P.257-263.
Schultz A.H. 1963. Age changes, sex differences and variability as factor in the classification of primates // Washburn S.L. (ed.). Classification and Human Evolution. Chicago. P.85-115.

Smith H.F., Terhune C.E. \& Lockwood C.A. 2007. Genetic, geographic and environmental correlates of human temporal bone variation // American Journal of Physical Anthropology. Vol.134. P.312-322.

Sonek J.D., Mckenna D., Webb D., Croom C. \& Nicolaides K. 2003. Nasal bone length throughout gestation: normal ranges based on 3537 fetal ultrasound measurements // Ultrasound in Obstetrics \& Gynecology. Vol.21. No.2. P.152-155.

Sperber G.H. 2001. Craniofacial Development. Hamilton, BC: Decker Inc. 220 p.

Sysak N.S. 1960. [Data on the age morphology of the human skull] // Proceedings of the Institute of Ethnography, New Series. T.50. P.29-41 [in Russian].

Thomson A. \& Buxton L.H.D. 1923. Man's nasal index in relation to certain climatic conditions // Journal of the Royal Anthropological Institute. Vol.53. P.92-122.

Vidarsdóttir U.S., O'Higgins P. \& Stringer C. 2002. A geometric morphometric study of regional differences in the ontogeny of the modern human facial skeleton // Journal of Anatomy.Vol.201. No.1. P.211-229.

Wagner G.P. \& Altenberg L. 1996. Complex adaptations and the evolution of evolvability // Evolution. Vol.50. P.967976.

Woo T.L. \& Morant G.M. A biomechanical study of the "flatness" of the facial skeleton in man // Biometrika. Vol.26. P.196-250.

Wu P., Jiang T.-X., Suksaweang S., Widelitz R.B. \& Chuong C.-M. 2004. Molecular shaping of the beak // Science. Vol.305. P.1465-1466.

Yokley T.R. 2009. Ecogeographic variation in human nasal passages // American Journal of Physical Anthropology. Vol.138. No.1. P.11-22. 